\title{
Strengthening Scholarship in Research on Implementation and Enforcement Architecture for Carbon Dioxide Emissions Reduction through Postdoctoral Research Programme
}

\author{
Kola O Odeku \\ Faculty of Management and Law, School of Law, \\ University of Limpopo, South Africa \\ E-mail:kooacademics@gmail.com
}

Doi:10.5901/mjss.2013.v4n14p819

\begin{abstract}
Climate change and global warming impacts are manifesting on a daily basis all over the world. Reports of the catastrophic weather events are always being aired in the news showing huge and massive destruction to property and life. Carbon emissions by both industrialised and non-industrialised nations are the main causes of global warming and climate change. While the developed nations are making frantic efforts through innovations and technologies to adapt to the changes in the climate, the developing countries do not have the capacity to develop such technologies hence unable to adapt to the climate change, leaving them with mitigation options. Against this backdrop, the school of law, on the initiative of the Dean, Faculty of Management and Law, University of Limpopo, South Africa has developed a postdoctoral research programme. Under the programme, study to address the issues of carbon emissions from the perspectives of implementation and enforcement of legal and policy frameworks on emissions reduction will be conducted. To achieve this, there is need to involve a postdoctoral research fellow that will work in conjunction with the programme leader. Pursuant to this, the study seeks to investigate how implementation and enforcement of policy and law on carbon emissions reduction could be strengthened as part of mitigation strategy. The study highlights the importance of capacity building and development in the areas of climate law and policy in order to position staff members of government and private institutions on how to ensure credible and sustainable implementation and enforcement of emissions reduction policy and legal frameworks. To this end, the need for high quality training of postgraduate students under the programme at the university will invariably capacitate the students and make them to become experts, thereby making them to provide services to emitters on how to curb their emissions and consequences for failure to comply.
\end{abstract}

Keywords: Postdoctoral Fellow, Fossil fuel, Carbon emissions, Global climate change, Policy and Legal Interventions.

\section{Introduction}

The issues surrounding global climate change and sustainable development are increasingly becoming trans-disciplinary in nature (Najam et al, 2003). It is generally accepted that emissions of noxious gasses as a result of human activities are causing global warming and climate change. Prominent among them is the emission of carbon dioxide to the atmosphere. Scholars from different disciplines have researched extensively by reporting on how best to reduce or curb the 'heat' (Christianson, 1999). In the same vein, governments around the world have continuously been putting in place various implementable strategic interventions and laws on how best to bring down the 'heat' without compromising the delivery of socio-economic amenities and services to the people. Law as a discipline plays and will continue to play a significant role in regulating these human activities that are contributing to and causing global climate change through implementation and enforcement of laws on emissions reduction (Hester and Harrison, 2002).

The focus of this study is thus to find solutions to the problem of severe and bizarre weather events caused by human activities through the burning of fossil fuels now threatening human existence. Law could be used as a catalyst for ensuring practical implementation and enforcement of carbon emissions reduction (Yang, 2008). This can only become achievable if there is robust wherewithal in terms of capacity to deliver. In South Africa, theoretically, there is dearth of statutory legislations on emissions reduction as well as a paucity of personnel with the capacity to implement and enforce the law. As a result of this legislation and capacity gap, perpetrators are usually not sanctioned thereby promoting a culture of impunity.

The concern is that developing countries of the world are hardest hit and affected (Odeku and Meyer, 2010). Currently there are manifestations of weather catastrophes destroying both properties and human beings on the African 
continent. The situation is exacerbated by the fact that African countries are the most vulnerable because of lack of adaptive and mitigation capacity to global climate change. South Africa, a developing country, is vulnerable because of its massive and intensive use of cheap coal to generate power for its energy intensive industrial activities. Coal is fossil fuel, it emits carbon dioxide that contributes to and causes global climate change. This study seeks to present and articulate in clear terms how this will be achieved and accentuates this with the proper political and administrative wills. It is feasible to control emissions and at the same time, responsibly grow the economy and deliver sustainable social economics goods and services to the people.

This study therefore reviews the broad approaches taken for the purpose of carbon emissions reduction through the building of research capacity which will continue to address the issues surrounding the hazards of carbon dioxide emissions in order to gradually reduce emissions and at a point in time, stop emissions entirely (Jorgensen and Siegel 2009).

\section{Rationale Behind the Study}

This anticipated study comprises a wide niche area of the law that has so far been relatively underexplored. The United Nations has enjoined all governments of the world to take steps to curb the surge of climate change and global warming (Meyer and Odeku, 2009). However, the majority of the developing countries' government ministries and departments do not have the requisite skills and capacity to curb emissions from industries. Even though the developed countries are the 'global warming-perpetrators' by their massive burning of fossil fuels during the periods of industrial revolutions, the developing countries are enjoined not to follow this unsustainable developmental path (Meadowcroft, 2007). Consequent upon this, while the developing countries are encouraged to grow their economy in order to deliver socio economic goods and services, it is expected that this would be done reasonably and sustainably (Rodrik, 2008). Against this backdrop, caution and self-restraint are needed in order to control developmental activities that will aggravate the problem (Chambers, 2005). Toward this end, there should be close monitoring, control, implementation and enforcement of all interventions that will prevent emissions. The potent tools to achieve these are numerous interventions and laws that have been put in place or being implemented and enforced. The application and enforcement of this will discourage and prevent developing countries from replicating what the developed countries have been accused of doing for the past 200 years. More importantly, there is need for developing countries to ensure holistic interventions in emissions reduction because they are vulnerable and do not have capacity to adapt (Yamin et al. 2005). Therefore, starting from home, sanctions and punishments contained in different carbon emissions laws will make possible gradual transition to emissions reduction.

The study seeks to promote and ensure an environment that is not harmful to the health and well-being of developing countries and protect the environment for the benefit of present and future generations. The right to clean environment and sustainable development contained in Section 24 of the Constitution of the Republic of South Africa will become practicable and realisable through the implementation and enforcement of the section. Section 24 of the Constitution also compels everyone to take reasonable steps to prevent pollution and ecological degradation, promote conservation and secure ecologically sustainable development and use of natural resources. Given the Constitutional imperative, the reason why this project is viable and needs to be pursed vigorously and the findings will serve as an impetus to reduce carbon emissions making the world a better place to live. The overall benefit will be the achievement of the Outcome 10 vision of the Environmental Sector Plan vision which seeks to ensure: "A prosperous and equitable society living in harmony with our natural resources" (DEA, 2012). Pursuant to this, both natural and human resources are expected to provide and promote common good for all in order to continue to sustain "A South Africa where environmental assets and natural resources are valued, protected and continually enhanced"( DEA, 2012).

Therefore, the key rationale for the Post-Doctoral Research Fellow Programme is, according to Msweli (2013), to "strengthen the identified niche areas within academic units in the Faculty and deepen expertise in the identified niche areas. Additionally, the programme presents an opportunity to strengthen the skills identified to advance the scholarly mission of the Faculty. The Faculty of Management and Law consider the Post-Doctoral Research Fellow Programme essential for driving innovation and research aligned to University of Limpopo of finding solutions for Africa." Considering that research is the driver of high quality pedagogy, the promotion of scholarship in research in the niche area of carbon emissions reduction will ultimately be linked to improved high quality standard of pedagogy to the environmental and climate law students. 


\section{Gap in Knowledge and Problem Statement}

While research on environmental law and management is well documented in South Africa, the same cannot be said of the area of implementation and enforcement of carbon emissions. Against this backdrop, there is paucity of scholarly information on how to implement and enforce the law on carbon emissions and make perpetrators accountable and be held civilly or criminally liable. This has thus created a huge lacuna. Consequently, a lot of climate culprits have escaped and will continue to escape sanctions and therefore continue polluting activities with impunity.

Against the above revealed disturbing problem which may lead to unimaginable consequences if nothing is done by taking responsibility, this programme seeks to dig deeper into various laws already put in place to curb carbon emissions by engaging in critical in-depth research analysis on how they can be practically implemented and enforced in order to attain the desired result of clean and sustainable planet for all generations.

\section{Research Aim and Objectives}

The aims and objectives are informed by the knowledge gap in carbon emissions reduction which thus tends to make perpetrators and polluters escape liability thereby promoting culture of impunity. Against the backdrop of this, the key aims and objectives that underpinned what the programme sets out to achieve are articulated thus:

\subsection{Aim of the study}

The key aim of the study is to show that by implementing and enforcing various laws on carbon emissions causing global warming, the emissions will reduce and gradually abate and culminate in a clean and sustainable environment. Towards this end, the likelihood of the scientific predictions of weather catastrophes as a result of global warming will not manifest. In order to achieve this, the study seeks to accentuate the importance of capacity development in issues relating to emissions reduction and curbing global climate change in general. More importantly, the study advocates the need to bring polluters and climate culprits to book. Pursuant to this, South Africa will be seen to 'walk the talk' as explicitly articulated in numerous international and national instruments on emissions reduction.

\subsection{Objectives of the Study}

The key objective of the study is to examine the implementation and enforcement of laws on carbon emissions as panacea for curbing global climate change. Other objectives arising from and relevant to the key objectives are:

1. Showing that failure or inaction of the people who are giving the responsibility to implement and enforcement various instruments on carbon emissions reduction is the main reason for the continued increase in emissions with impunity by the perpetrators. Consequent upon this, the study emphasises the need for everyone to act responsibly and do what is right with appropriate measures taken against culprits both criminally and otherwise.... To this end, prosecuting authority and their staff members will benefit from this project. In the same vein, legal advisers working in various companies where carbon emissions are emitted will also benefit as they will be exposed to and gained knowledge on how not to contravene the laws during their company's industrial activities. By so doing, they will be able to offer the best advice in the circumstances in order not to cross the red lines.

2. Capacitating legal minds, as part of environmental and climate change "capacity-transformation", by providing high standard Masters and Doctoral studies and degrees in laws in this wide niche area. This is important because few legal minds and lawyers received training in this regard at the postgraduate levels. Due to this lack of capacity, there is a negative impact on how they evaluate and apply environmental and climate laws at the workplace. More importantly, very few black academics are pursuing career in this area of law. Registering and training black South African academic, will enhance and improve their knowledge capacity translating to dissemination of robust and high standard of pedagogy of teaching and learning at the tertiary institutions.

\section{Research Methodology}

This research will use substantially, qualitative research method generally acceptable in legal research activities. Information and materials will be sourced from the internet, hence, the researchers will be involved in desktop computer 
research activities in order to read extensively literature on the subject area and have up-to date information on the issues surrounding the use of law to retard and curb emissions. Researchers will also consult and use various national and international instruments and laws to examine and analyse issues for purposes of finding solutions to the identified problem. Consequently, comparative research approach will be prominent in this study. Good examples and lessons from other jurisdictions on how laws are being used and enforced to curb emissions will be drawn and lessons will be learnt from them. Due to the nature of global climate change and international initiatives to curb emissions causing these changes, the researchers will also engage in trans-disciplinary studies in view of the comprehensive problems inherent in global climate change by contacting, partnering, collaborating and seeking relevant and useful information from other disciplines and giving full acknowledgement for their contributions This approach seems to be viable and sustainable. According to Burns et al. (2006) who describes sustainable research as:

"research that produces knowledge that is immediately useful for policy and management... has as its goal the integration of science and technology with other sources of knowledge to solve problems and to inform decisions...both the problem to be solved and the knowledge needed to solve it are defined collaboratively in the conduct of sustainability science...focuses on the interface between human society and the environment upon which societal wellbeing depends...aims to improve understanding of how society shapes the environment and how the environment, in turn, shapes society. Furthermore, In view of the recently approved Environment Sector Research, Development and Evidence (R,D\&E) framework was approved by MINMEC on 08 June 2012 which seeks to pursue and focus on the collection of solid evidences that can be used in support of environment sector policy decisions and for the achievement of sector priorities, this approach seeks to develop a more rigorous approach that gathers, critically appraises and uses high quality research evidence to inform policy-making and professional practice. The essence of all these are to strengthen collaborative research activities of researchers and work closely with Policy-makers and researchers need to work more closely together by means of established, regular and trusting interaction and dialogue (DEA, 2012).

The use of all relevant legal lexicons such as case law, statutes, pieces of legislations, policies, initiatives, strategies, measures and interventions will definitely be the sin qua non to achieving the programme.

\section{Literature Review}

Even though South Africa is a Non-Annex I country party to the UNFCCC and it is also party to the Kyoto Protocol 1997, which means that the country is not under any international obligation to reduce its greenhouse gas emissions (Mumma and Hodas 2007), South Africa has volunteered to reduce its greenhouse gas emissions by $34 \%$ below a business as usual emissions growth by 2020 (business as usual is the baseline which assumes that future development trends follow those of the past and no changes in policies will take place), and a 42\% reduction by 2025 (Newmarch 2013). This target is achievable if the country is able to receive appropriate finance, technology and capacity building support from developed countries. With regard to capacity building, the country, has, on its own, launched various initiatives and strategies to achieve this locally. The assistance from the developed country will thus compliment the local initiatives.

Furthermore, in its bid to commit to continue emissions reduction, the country has put in place various policy processes to achieve this and the most recent of which is the National Climate Change Response Policy (October 2011) (National Policy), (Winkler and Marquand 2009). The National Policy is the latest in a number of milestones in climate change policy development, which include but not limited to; National Climate Change Response Strategy (September 2004), South Africa National Climate Change Conference, November 2005, Long Term Mitigation Strategy Scenarios of 2006 and beyond, African National Congress (ANC) Polokwane Summit of December 2007, South African Climate Change Policy Summit of March 2009, Green Economy Summit of May 2010 and National Climate Change Response Green Paper of November 2010).

It is, therefore, important to point out that there is scarcity of skills in the fields of environmental and climate change disciplines in South Africa, recognising this expertise gap, the Department of Environmental Affairs IDEA, 2009) rolled out a strategic policy document to address scarcity and strengthen existing skills in these disciplines. Emphasising on the benefit of strengthening skills in these areas, the (DEA, 2009:1) asserted that:

"Human Capital Development Strategy (HCDS) arises out of the constitutional imperative for a clean, healthy environment that benefits current and future generations, and the impetus to strengthen opportunities associated with a green economy for South Africa. Its time frame is 2009-2014, which is aligned with the MTSF of 2009-2014. The MTSF prioritises skills development in South Africa, and emphasises the importance of quality in the education, training and skills development process. South Africa has developed a suite of legislation associated with the National Environmental Management Act No. 102 of 1998. The implementation of this legislation remains a work in progress and 
cannot be done without adequate attention to human capital development. The National Human Resources Development Strategy for South Africa (2009-2014) identifies the importance of implementing skills development initiatives that respond to South Africa's social and economic needs, and development of skills that improve service delivery."

Against the backdrop of the need to strengthen capacity and skills development in environmental disciplines, the University of Limpopo has responded by initiating and strengthening its teaching and research activities to give effect to the ideals and aspiration of the DEA. These ideals are in line with the motto of the University of Limpopo which is "finding solutions for Africa." And also resonates perfectly with the mission and vision of the University which states that the University is:

\begin{abstract}
"a world-class African university, which responds to education, research and community needs of our society through partnerships and knowledge generation, continuing the tradition of empowerment. To be a leading African university epitomising excellence and global competitiveness, addressing the needs of rural communities through innovative ideas." (University of Limpopo, 2013).
\end{abstract}

The school of law, a distinctive school within the Faculty of Management and Law at the University of Limpopo, is therefore committed to the advancement of knowledge and finding solutions for Africa through scholarship in teaching, research and community engagement. With regard to the research activities, the school of law has set the following research goals in carbon emissions reduction to improve academic capacity of staff; increase overall research outputs and increase the number of active and established researchers. To this end, the school is committed to implement the following key objectives articulated in the document on the Developing Finance and Economic Transformation Centre (DFTC, 2013).

a. To establish niche areas by finding innovative and sustainable solutions which address the developmental challenges facing the world in general and southern Africa in particular through research;

b. To strengthen the research capacity in the university through multi-, inter- and trans-disciplinary (MIT) research;

c. To engage research fellows and post-doctoral fellows to embark on cutting-edge research;

d. To train young scientists and researchers;

e. To increase the research productivity of the department/school/university through research publications;

f. Attract external funding for research in specific research areas; and

g. To transform the Research Centre into a Centre of Excellence;

h. Seek intellectual property rights for the products and services developed in the Research Centre."

The programme has identified the right set of individuals to be trained as experts in generating and using knowledge which is only one of many essential steps in capacity building (Lansang et al. 2004). The Dean and the Director have created enabling research environment to enhance the productivity, output and the interest of the researchers. This is contrary to what used to obtain in the Faculty. Then, there was a lack of enabling environment which was characterised by incompetent leaders at the helms of affairs in the Faculty who spent time on trivial matters instead of promoting culture of research (Nchinda, 2002).

Developing and building the capacity to effectively carry out research on carbon emissions reduction in South Africa, is an integral part of the various government initiatives and strategic interventions to create sustainable knowledge systems and continuously improve the human and physical resources that will ensure clean environment and promote sustainable growth (Barraclough, 2005). This is in line with the Millennium Development Goals which seeks to achieve by 2015, capacity building to carry out multidisciplinary research in the context of sustainable clean development and curbing the surge of global carbon emissions. The vision to decarbonise South Africa is also informed by the human and environmental rights enshrined in section 24 of the Constitution, the provisions in the National Environmental Management Act (107 of 1998): provides for co-operative environmental governance based on the principles that everyone has the right to an environment that is not harmful to his or her health or well-being, and enabling the administration and enforcement of other environmental management laws. Practical priorities are captured in the Millennium Development Goals (MDG), Johannesburg Plan of Implementation (JPOI), and National Strategy for Sustainable Development (NSSD1) and other key government socio-economic policies (DEA, 2012).

With a suitable mentor anchoring the programme, this will enhance the intellectual environment in the School focusing specifically on how policy will be applied and law enforced to reduce carbon emissions. This will also prepare the postdoctoral fellow to develop his/her research skills and prepare him/her for an academic career. The core functions 
to be performed linked to the focus of the study are, to conduct research and publish research finding and results, provide mentorship and assistance with regard to postgraduate student supervision and, contribute to the promotion of an intellectual environment in the School and within the University.

\section{Students and Staff Development}

This programme will be very intensive and robust, in order to achieve the set goals. ; For the take-off, the project will attract: one post-doctoral fellow, two doctoral candidates and eight masters students that will form part of the pioneerteam to conduct a critical in-depth research into the implementation architecture to retard and curb carbon dioxide emissions. Staff members who intend to focus on this research path are encouraged to join the team either as candidates, students or collaborators.

After the take-off, the project will graduate the first set of Masters Students in 2015. The implication of this is that another set of eight students will be admitted in 2015 in order to make students and staff development a 'going-concern.' Outstanding masters students within the programme will be motivated to explore the possibility of pursuing doctorate. In essence, the programme will continuously be the main source from which the doctoral students will be sourced.

\section{The Research Impact}

While the creation of the research project is to disseminate findings that will contribute to the body of knowledge by improving understanding and generate new knowledge, it will also be beneficial to a whole range of private and government institutions by providing a robustly enhanced understanding in the areas of successful possible sanctions and liabilities against perpetrators for failure to observe and comply with the laws on carbon emissions reduction.

\section{Research Plan and Activities}

The Principal Investigator has a proven robust research records and outputs. He has supervised quite a numerous postgraduate students and intends to continue on this path and trajectory offering robust-contemporary academic and scholarly leadership-mentoring that will lead to the successful implementation and conclusion of this project: Pursuant to this, the activities are detailed below:

1. As indicated in the methodology above, from the outset in January 2014, the researchers will engage with and use massive literature from scholarly works, environmental and climate legislation and policies locally, nationally and internationally, and all scholarly lexicons pertaining and relevant to emissions reduction to proffer and find solutions to the problem. Consequent upon this, all the researchers will partake in sourcing of relevant materials and literature. The researchers will use library materials and, if there is need to travel to libraries outside the host University, researchers and students will be motivated to go and use those libraries that have the relevant information and scholarly resources.

2. The principal investigator would be tasked with providing assistance in conceptualisation of the research subtopics and provide leadership in technical aspects of the writing of the project.

3. The principal investigator has developed sub-topics from the main project which can be researched and broadened to full-blown, full-time Masters by research dissertations. Masters students are eligible to avail themselves of these topics or other topics relevant to the goals of the project.

4. The post-doctoral candidate will work under the supervision of the principal investigator and contribute by way of providing guidance and sub-mentorship to the Masters students in writing acceptable proposals, improving their writing skills and ensuring that they do not derail from the focus of research.

5. More importantly, all researchers and participants will have to undertake any or other activities that will inadvertently 'crop-up' during the course of the project but such activities must be part of and be relevant to the approved project and the goals.

\section{Conclusion}

Pursuing study that focuses on carbon emissions reduction is ideal and noble. However, the findings are not supposed to be housed within the academia alone, it should be seen to have a positive impact on the society and humanity. To this end, the outcome of this programme will have substantial positive impact on the environment because there will be 
emissions reduction which will make the atmosphere cleaner and at the same time, promotes sustainable socio economic growth and development. As part of capacity building, the programme will produce people who have the requisite expertise and skills that will be used to offer advices at the work places whether in private or government institutions.

\section{Recommendations}

Global climate change phenomenon is a cross-cutting issue; it is not peculiar to a particular country. Poor developing countries that do not have appropriate resilience are the hardest hit. This is the reason why all hands should be on the deck and the fight against carbon dioxide emissions should be the responsibility of everybody. While research into emissions reduction is welcomed, more needs to be done in terms of applying and implementing solutions and outcomes of the research output in practical terms.

\section{References}

Barraclough SL 2005. In Quest of Sustainable Development. From http://scholar.google.co.za/scholar?hl=en\&q =+++barraclough+sl+2005.+in+quest+of+sustainable+development\%2c+overarching+concerns+paper+number+4+september+2 005sdtp=. (Retrieved September 4, 2013).

Burns M, Audouin M, Weaver A. 2006. Advancing sustainability science in South Africa. South African Journal of Science, 102: 379-384. Chambers R 2005. Ideas for development, Earthscan Publishers, London, UK.

Christianson G 1999. Greenhouse: the 200-year story of global warming, Walker publishing Company Incorporation, Vancouvers, Canada, pp.24-39.

DEA 2012. Department of Environmental Affairs, South Africa. Environment Sector Research, Development and Evidence framework, An approach to enhance sector science-policy interface and evidence-based policy making. From https://www.environment.gov.za/sites/default/files/docs/environmental_research_framework.pdf. (Retrieved December 19, 2013).

DEA, 2009. Department of Environmental Affairs. Human Capital Development Strategy Environmental Sector A systems approach to skills development to support the Environmental Sector Strategic Plan 2009 - 2014. From https://www.environment.gov.za /sites/default/files/docs/human_capital_strategy_environmental_sector.pdf. (Retrieved November 22, 2013).

DFTC, 2013. Developing Finance and Economic Transformation Centre. Faculty of Management and Law, University of Limpopo, South Africa.

Hester RE, Harrison RM 2002. Global environmental change, The Royal Society of Chemistry, Cambridge, UK.

Jorgensen SL, Siegel PB 2009. Addressing human vulnerability to climate change: Toward a 'no-regrets' approach, Global Environmental Change, 19(1):89-99.

Lansang MA, Dennis R, 2004. Building capacity in health research in the developing world, Bulletin of the World Health Organization, Bulletin of the World Health Organ 82(10): 1-6.

Meadowcroft J 2007. National sustainable development strategies: features, challenges and reflexivity, Environmental Policy and Governance 17(3):152-163.

Meyer E, Odeku KO 2009. Climate Change, Energy and Sustainable Development in South Africa: Developing the African Continent at the Crossroads, Sustainable Development Law \& Policy Journal, American University Washington College of Law, 10(2):49-53.

Msweli P 2013. Faculty of Management and Law Guidelines for Awarding Post-Doctoral Research Fellow, Published by FML, University of Limpopo, Turfloop, South Africa.

Mumma A, Hodas D 2007. Designing a Global Post-Kyoto Climate Change Protocol that Advances Human Development, Georgia International Environmental Law Review, 20:619-629.

Najam A, Rahman AA, Huq S, Sokona Y 2003. Integrating sustainable development into the Fourth Assessment Report of the Intergovernmental Panel on Climate Change, Climate Policy, 3(1):7-17.

Nchinda TC 2002. Research capacity strengthening in the South, Social Science \& Medicine, 54(11):1699-1711.

Newmarch J 2013.Does money grow on trees? : the role of climate change finance in South Africa. From http://wiredspace.wits.ac.za /handle/10539/13177. (Retrieved December 1, 2013).

Odeku K, Meyer E, 2010. Climate Change Surge: Implementing Stringent Mitigation and Adaptation Strategies in South Africa, Journal of African Law, Cambridge University Press, 54(2):159-183.

Ramanathan V, Carmichael G 2008. Global and regional climate changes due to black carbon, Nature Geoscience 1:221-227. Rodrik D 2008. One economics, many recipes: globalization, institutions, and economic growth, Princeton University Press, New Jersey, USA.

University of Limpopo, 2013. Mission and Vision. From http://www.ul.ac.za/index.php?Entity=UL Historical Background. (Retrieved June 29, 2013).

Winkler H, Marquand A 2009. Changing development paths: From an energy-intensive to low-carbon economy in South Africa, Climate and Development, 1(1): 47-65.

Yamin F, Rahman A, Hug S 2005. Vulnerability, Adaptation and Climate Disasters: A Conceptual Overview, Institute of Development 
Studies (IDS) Bulletin, 36(4):1-14.

Yang T 2008. The Emergence of Global Environmental Law. From http://works.bepress.com/tseming_yang/1. (Retrieved September 19, 2013.

Zaelke D, Cameron J 1989. Global Warming and Climate Change-An Overview of the International Legal Process, American University Journal of International Law and Policy, 5:249-252. 